\title{
MRS Forum on the Materials Science and Engineering Study
}

\section{Introduction}

At the 1986 MRS Fall Meeting in Boston a Forum on the Materials Science and Engineering (MSE) Study was organized by MRS to offer its members the opportunity to learn of progress by and to contribute to the MSE Study that was commissioned by the National Research Council at the request of the National Academy of Sciences and the National Academy of Engineering. The goals of the MSE Study are to develop and present a unified view of recent progress in materials science and engineering to identify new directions in the field, and to assess future opportunities and needs. Because of the scope and widespread support of this study, it is expected to have a strong influence on congressional and administrative policy and thereby the funding and future directions of materials research. This study represents the first broad assessment of materials science since the COSMAT Report of the early 1970s.

\section{Background}

The MSE Study is jointly sponsored by the Solid State Sciences Committee (SSSC) and the National Materials Advisory Board (NMAB), and the chairs of these respective committees serve as cochairs of the Steering Committee of the MSE Study. Praveen Chaudhari of IBM and Merton Flemings of MIT were selected as cochairs of the MSE Study. The study is organized into five panels, and each panel is structured with a chair and two cochairs chosen to strike a balance between university, industry, and government representation. The membership of each panel is intended to have a similar balance.

Editor's Note: See the November/December 1986 issue of the MRS BULLETIN, p. 41, for a complete list of MSE Study panel chairs and members. For descriptions of the study, its objectives, and progress, see the following issues of the MRS BULLETIN: Vol. XI No. 3 (1986) p. 30; Vol. XI No. 4 (1986) p. 40; and Vol. XII No. 1 (1987) p. 75

As can be deduced from the titles of the panels, the study is charged with a broad assessment of materials science and engineering. Items for study include an evaluation of research needs and opportunities in MSE, a definition of the field of MSE and its impact on society, an assessment of the roles of the federal and private sectors in achieving a balanced materials effort, the effectiveness of the materials infrastructure in developing and commercializing new technologies, the effectiveness of materials research and education at our universities, and the role of international cooperation and competition in materials science and engineering.
Another important goal of the study is to bring a sense of unity to the materials science community. Because materials science is such a diverse field with needs and interests that bridge the entire spectrum of science and technology, it is difficult to conceive that a single discipline or entity could speak eloquently for all factions. Nevertheless, there are strong political, practical, and economic reasons why such a cooperative sense is needed. There is little doubt that materials science suffers politically from not having a spokesgroup recognizable by Congress and the federal agencies when they decide scientific and funding priorities. The consequence is that when disagreements such as the bigversus-small science issue arise, the entire community suffers because of a lack of unity and consensus.

From a practical and economic point of view, materials research and engineering is having an ever-increasing impact on all fields of science and technology, and a lack affect the economic competitiveness and national well-being of the United States. For example, a critical area affecting the U.S. electronics industry is the need for techniques; and government projects from fusion reactors to weapons systems hinge on materials development. The logic for more unification of materials science is reflected in the trends of several major institutions toward interdisciplinarity as a way of facilitating materials research. The national laboratories have long recognized interdisciplinary $R \& D$ as the most effective of unity has the potential to adversely new materials and materials processing

way to solve large project problems; the materials research laboratories at universities resulted from early recognition of the same approach; and more recently the $\mathrm{Na}$ tional Science Foundation has encouraged interdisciplinarity on university campuses through the formation of Engineering Research Centers. A more unified materials community should benefit all of materials science, and hopefully, the MSE Study can further this goal.

The success of MRS itself is testimony to the need and benefits of a more unified materials community. MRS is unique among professional societies in that its base is not in service to a particular discipline, such as metals or ceramics, but in a multidisciplinary approach to materials research and engineering in general. Consequently, our membership felt a close kinship with the goals of the MSE Study from the very beginning, and MRS was quick to propose action when the chairs of MSE Study called for input from the professional societies to the study.

The MRS response was twofold. First, it solicited contributions from all its members in a general call for papers that went out in June 1986. These brief communications were collected and published in a book entitled Communications on the Materials Science and Engineering Study, which was available at the MRS 1986 Fall Meeting in Boston and was given to the MSE Study representatives for consideration in their report. The second response was the organization of the Forum on the MSE Study, held during the 1986 MRS Fall Meeting.

Continued

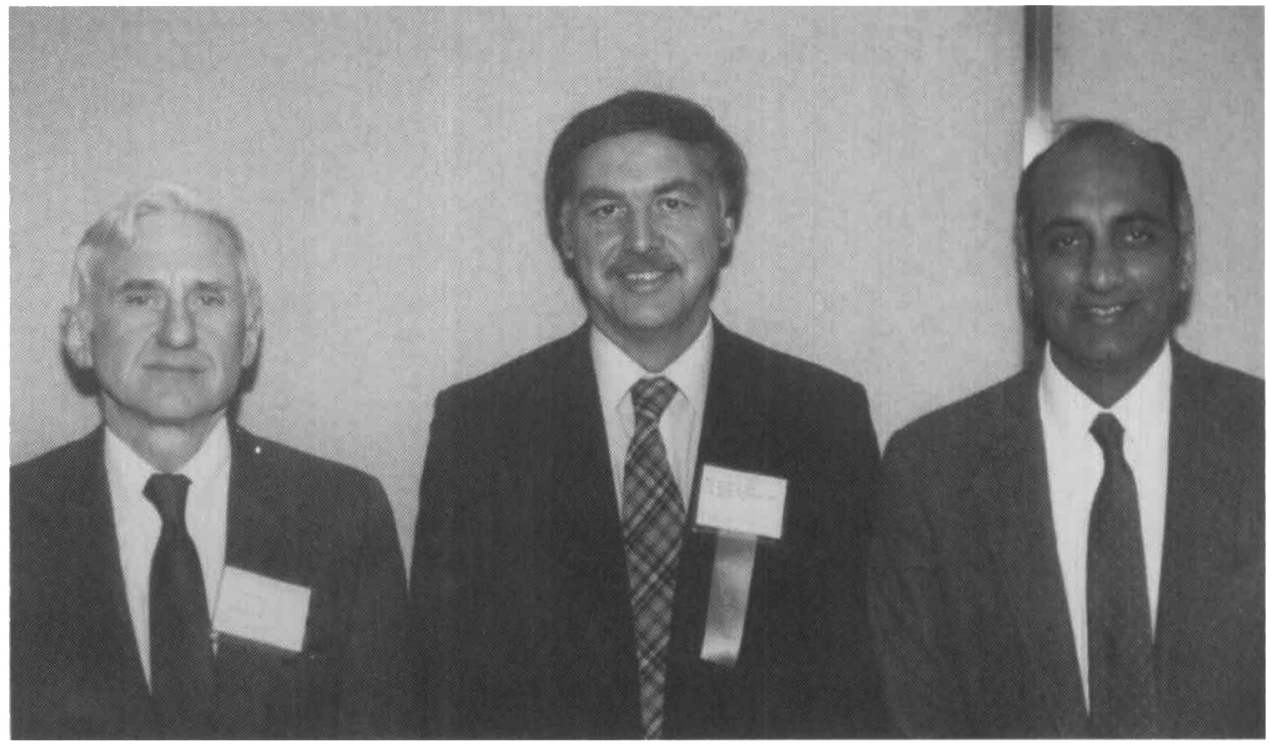

B.R. Appleton (center), chairman of the MRS Forum on the MSE Study, with MSE Study chairs M. Flemings (left) of MIT and P. Chaudhari (right) of IBM. 


\section{MRS Forum on the MSE Study}

The forum was held on Thursday, December 4, and Friday, December 5, during the 1986 MRS Fall Meeting. It was chaired by Bill Appleton for MRS, and the MSE Study was represented by Praveen Chaudhari. The forum was organized into five sessions that dealt with each of the five panels of the MSE Study. Each session opened with an overview talk by the chairman or vice chairman of that panel to inform the attendees of the progress and future plans of the panel. This was followed by a discussion session to allow MRS members to offer direct input and suggestions into the study. Papers selected by the MRS session chairman and the MSE panel representative from among those submitted by MRS members to the communications book mentioned earlier were also presented in each session, and a general discussion followed these presentations. Since it is not possible or timely to recount the entire proceedings of the forum, only selected highlights are summarized here that, we hope, will be of interest to MRS members. (The complete program for the forum is listed in the MRS BULLETIN, Vol. XI No. 6 [1986] p. 40.)

\section{Panel 1: Research Opportunities and Needs in MSE}

Session 1 was cochaired by Frank Fradin of Argonne National Laboratory representing MRS, and by James Langer, chairman of MSE Study Panel 1, who presented the overview. The work of the panel has been divided into several tasks with the intention to survey opportunities and needs in the academic, industrial, and federal sectors. The industrial survey of needs currently under way includes eight sub-panels from the various industry sectors, such as electronics and automotive. The survey of federal needs is similarly under way with the intention to consult all the major agencies such as Navy, Air Force, NASA, and DOE. Panel 1 also had plans for a work-

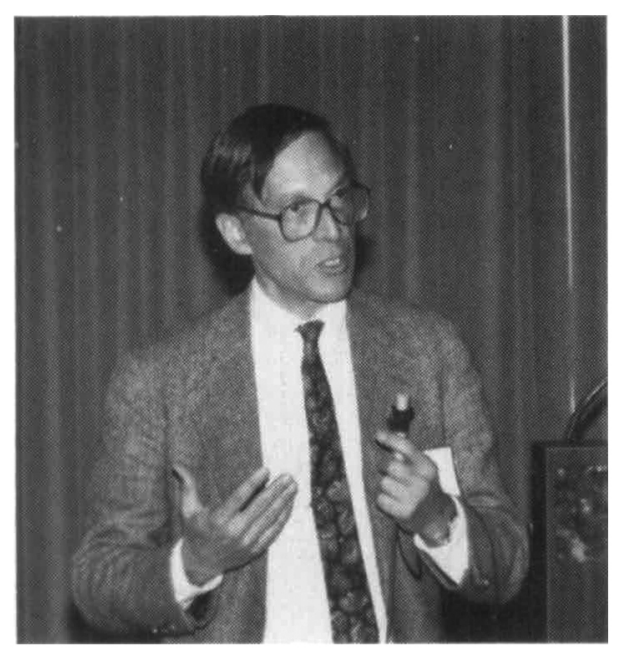

J. Langer (University of California, Santa Barbara) chairman of MSE Study Panel 1. shop with the primary focus to be on research opportunities.

The workshop was later held at NAS/ NAE in Washington, DC on January 22-23, 1987. The workshop reviewed previous studies such as the COSMAT Report; assessed the role of synthesis, characterization, processing, and performance in materials research as a way of taking an interdisciplinary view of all of MSE; considered analysis and modeling as applicable to all of MSE; and assessed opportunities in artificially structured materials, biomaterials, and electronic, magnetic, photonic, and structural materials. The results from these various assessments will form the basis for the Panel 1 report.

A major concern expressed by MRS Forum attendees was that the list of speakers and institutions assembled for the workshop to overview research opportunities was almost exclusively academic. In particular, there were no representatives from government-sponsored laboratories, where a substantial fraction of all materials research in the United States is performed. The workshop also was structured so that materials engineering was not emphasized enough. Other comments included suggested additions to the topics being covered at the workshop, such as the addition of catalytic materials.

The clear message from the overview presentation and the contributed papers at the MRS Forum was that the enormous scope of this task is matched by the opportunity and excitement that exists in materials research. The talks from MRS members in this session presented an enviable menu of research on new materials, new materials processing methods, and exciting areas for future research. Some of the opportunities in materials science were summarized in the contributed paper session by E.N. Kaufmann, R.C. Dynes, W.L. Johnson, H. Wiedersich, M.B. Maple, M.L. Kaplan, D. Emin, and W.J. Nellis.

\section{Panel 2-Exploitation of MSE and Technology for National Welfare}

Session 2 was cochaired by MRS President Kathleen Taylor of General Motors Research Laboratories and by James $C$. Williams of Carnegie Mellon University. Williams, vice chairman of MSE Study Panel 2, gave the overview. This panel is examining how MSE affects the national economy and welfare with the premise that the issues surrounding technology transfer are a central indicator of this theme. The panel has held workshops and is planning more to examine the impacts of technology transfer. The first workshop was held on October 24, 1986 to examine whether technology transfer was specific to certain technologies. The various technologies examined were associated with liquid crystals, intermetallic compounds, carbon fibers, polymers for VLSI processing, optical fibers, structural ceramics for heat engines, and high performance magnets.

A second workshop, scheduled for December 9, 1986, planned to look at the effects of selected institutions and institutional factors on technology transfer. The institutions to be examined were Los Alamos National Laboratory as an example of national laboratories; Semiconductor Research Corporation as a semiconductor industry consortium; Bell Communications Research and the Microelectronics and Computer Consortium as multiclient institutions; and the Air Force Manufacturing Technology Program as an example of an institution that tries to transfer government technologies to useful practice. The institutional factors to be examined at this second workshop are legislation and policy, such as import and export controls; vertical integration and its effects; venture capital and its role in technology development; and the role of professional societies in disseminating information.

The evolving conclusions of Panel 2 as of the end of the first workshop (October 24, 1986) can be summarized:

(1) A focus on short-term return on investment hurts industrial competitiveness.

(2) A clear distinction must be made between national security and national competitiveness. Spending for national security serves a captive domestic need but is not necessarily a stimulus to national welfare.

(3) Decentralized profit responsibility tends to hurt technology sharing and transfer.

(4) Vertical integration can be helpful provided it is not neutralized by separate profit and loss responsibility at each step of the vertical integration.

(5) Entrepreneurship and venture capital startups were deemed by the panel to be overrated.

(6) The panel also concluded that there was far too much emphasis on proprietary and classified research and that this unduly impeded information transfer.

Some issues suggested by attendees for the panel's consideration were the effect of increasing governmental restrictions being placed on a wide range of technologies, the integration of materials and component design in systems, and the problems of transferring technology within a company. It was noted that the panel had significant representation from large business but no representation from small businesses, and an initiative was started to offer some representation from this sector to the panel. For consideration of institutional factors in workshop 2, it was noted that the characters of the weapons and nonweapons national laboratories are very different, and that Los Alamos National Laboratory was probably not a typical example. A followup comment noted that a major impediment

Continuec 


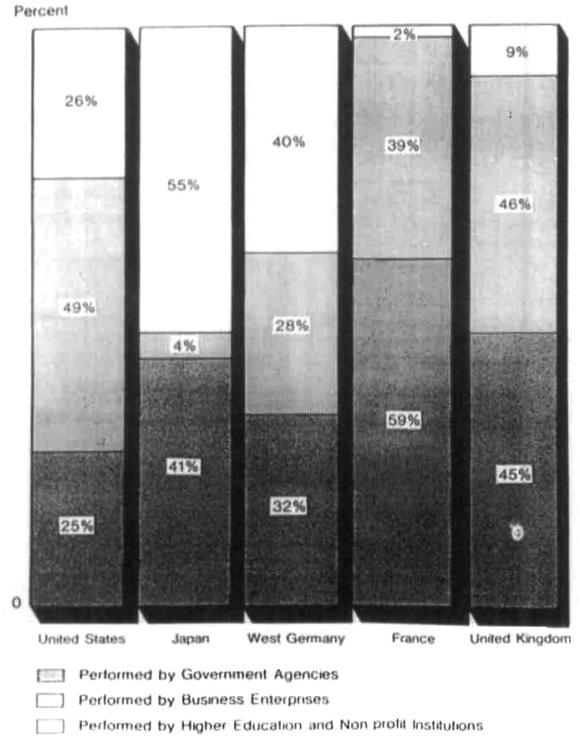

Figure 1. Use of government funds for R\&D in selected countries, 1981 (Panel 3 data).

to technology transfer from national laboratories was the intransigence of government lawyers, a comment elaborated by R.L. Schwoebel in the contributed paper session. Other papers were given by F.V. Wald and J. Rumble, Jr.

Panel 3-International Cooperation and Competition

Session 3 was cochaired by C.W. White of MRS and by Lyle H. Schwartz of the National Bureau of Standards. In his overview, Schwartz, chairman of MSE Study Panel 3, reviewed the charter that Panel 3 has set for itself:

(1) a quantitative assessment of international MSE activities,

(2) a determination of the differences and similarities in MSE activities,

(3) comparison of national MSE policies and strategies, and

(4) assessment of the role of MSE in industrial competition.

Because of the scope of this task the panel had to be somewhat selective in its assessments and focus on a few specific problems and a few pertinent countries. Three tasks have been initiated to accomplish this charge. The first is to perform a broad coverage of foreign MSE from existing literature and to assess scientific, programmatic, and statistical data. (See Figures 1 and 2.) The second information gathering is via a questionnaire on the role of MSE in national affairs. This questionnaire seeks subjective views from foreign MSE leaders asking them to deal with their MSE goals, strategy, and implementation of these. The third task involves case studies of broad areas such as steel, aircraft, VLSI materials, and ceramic heat engines. The goal is to assess how we are doing in some of these case areas in comparison with our competitors.
In the final report, in addition to assessat the impact through case studies, the panel will look at issues and strategies. Some of the issues that will be considered include the impact that a strong defense commitment has on U.S. MSE compared with countries like Japan, the role of national laboratories and how they should be utilized for MSE technology transfer, university $R \& D$ trends, industrial research cooperation, and the effect of multinational corporations and whether we are transferring technology to competitors.

The contributed papers by C.B. Duke, Fan painted a disturbing picture of the present status of U.S. competitiveness in the world in key areas such as electronic materials, advanced materials processing techniques, and manufacturing in general. Several recent NAS, NAE, NSF, and DOD reports were reviewed which recommended that a new approach was needed, such as new institutional arrangements that more effectively promote cooperation among government laboratories, universities, and industries. What was new in these appeals was the notion that governmental resources such as the national laboratories should be directed to enhance the ing the nature of MSE abroad and looking R.M. Osgood, Jr., J.M. Poate, and J.C.C.

worldwide competitive posture of critical industries such as the electronics industry.

\section{Panel 4-Research Resources in MSE}

Session 4 was cochaired by Elton $\mathrm{N}$. Kaufmann of Lawrence Livermore $\mathrm{Na}$. tional Laboratory and by MSE Study Panel 4 chairman Terry Loucks of Norton Company. The charter of Panel 4 is to assess the balance between people, equipment, facilities, and instrumentation from the various sectors of government, universities, and industry; to assess the current status of research resources in the United States; and to forecast the research resource requirements that will be needed in the future. This task of surveying current resources and forecasting future needs, like many of the others, is enormous and challenging.

Considerable effort has been directed so far to surveying needs with each selected area being considered from the government, university, and industry views. The areas surveyed include federal laboratory programs, major equipment facilities (synchrotrons, neutron reactors), intermediatescale facilities (MRLs), individual principal investigators, advanced manufacturing and processing, advanced instrumentation, and advanced processing of electronic

Continued
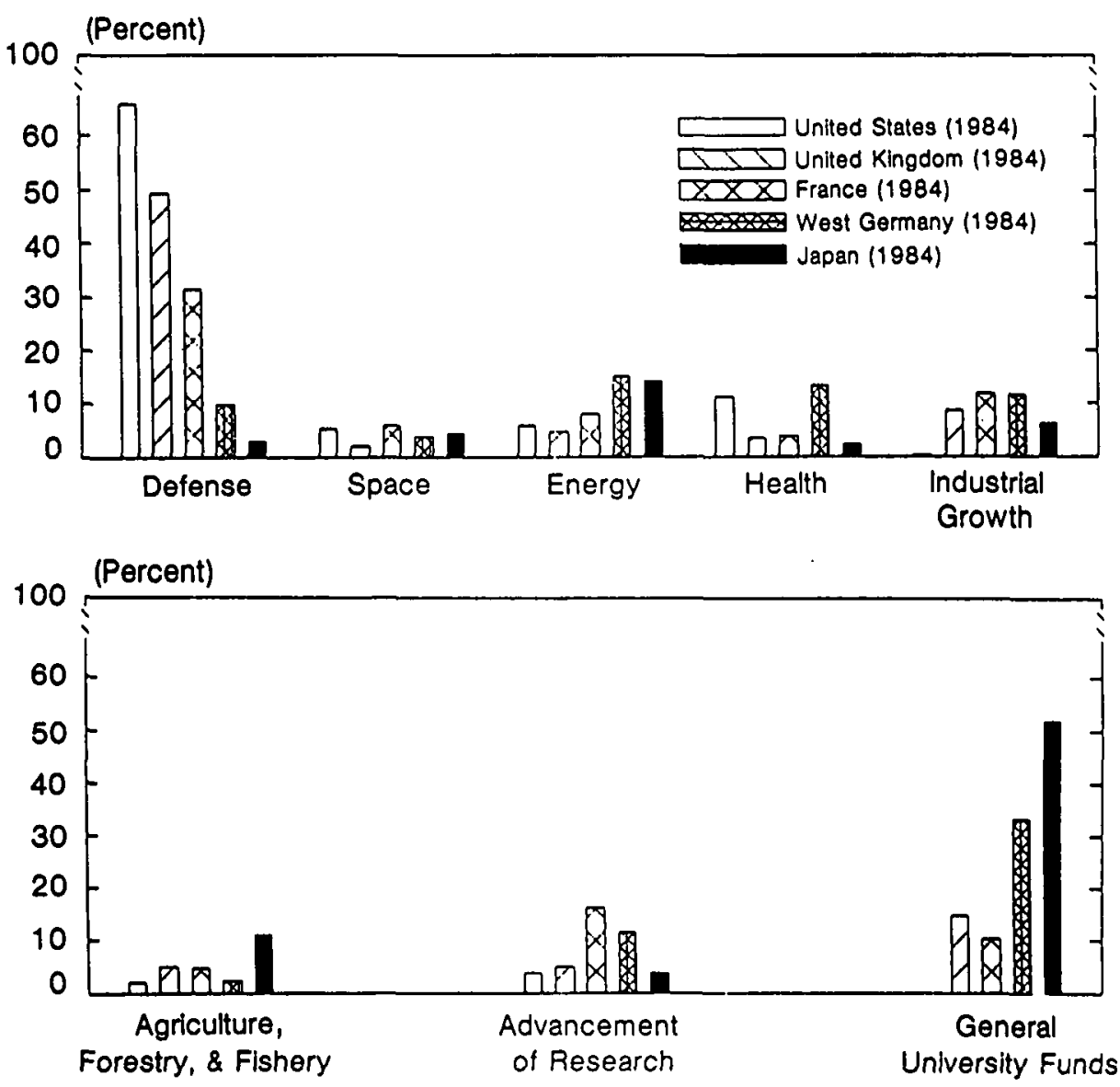

Figure 2. Distribution of government R\&D expenditures among selected objectives by country, 1984 (Panel 3 data). 


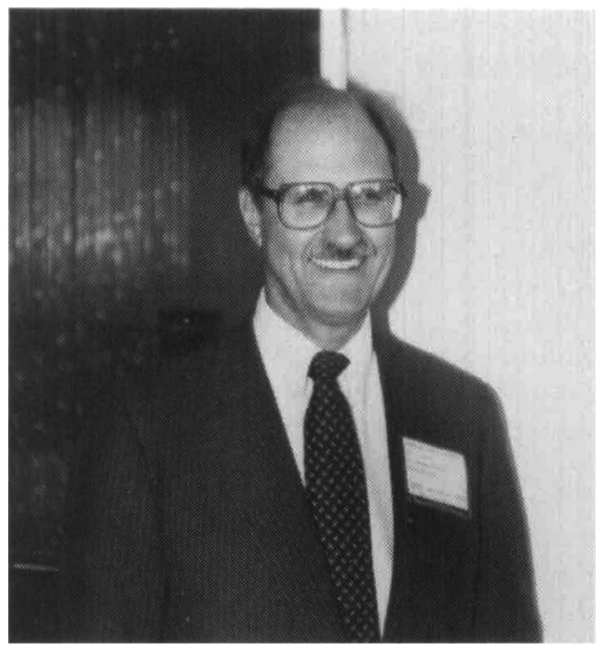

T. Loucks (Norton Company), chairman of MSE Study Panel 4.

materials. In assessing these areas, the final information will be structured into an information matrix divided into major facilities, intermediate-scale facilities, and individual principal investigators along one axis, and government, university, and industry along the second. Within a given matrix space the same multidisciplinary factors considered by Panel 1 (structure, synthesis, properties, performance, etc.) will be considered as well as specific needs of each. This requires close collaboration with Panel 1. The forecasting of needs is just beginning.

Support papers were given in the session by A. Bienenstock, B.W. Dodson, L.C. Ianniello, E.N. Kaufmann, and R.M. Moon.

\section{Panel 5-Education in MSE}

Session 5 was cochaired by Herbert $\mathrm{H}$. Johnson of Cornell representing MRS and by MSE Study Panel 5 chairman I.M. Bernstein of Carnegie Mellon University. Bernstein explained that the goals of this panel are to assess human resources and past, current, and future trends in materials education, both in traditional materials de- partments and in other science and engineering disciplines. The panel has organized four tasks to accomplish these goals. The first is to survey existing human resources for education in MSE. This will include the use of existing statistical data from a variety of university, government, and professional sources and the development of suitable questionnaires to gather new information. The second task is to identify future directions of education in MSE, including education in and out of materials departments. The third task is to identify needs and opportunities for increasing interdisciplinarity in MSE education. The final task is to identify needs and opportunities in lifelong education such as continuing education and recertification.

Some of the issues discussed and being considered by the panel included the difficulty in identifying what MSE is and how it could best be handled in educational institutions. For example, should there be an integrated, accreditable undergraduate MSE curriculum? The balance between science and engineering and the value of having interdisciplinary programs compared with conventional programs were also discussed.

\section{Summary Comments}

The MRS Forum on the MSE Study was in my opinion a resounding success for both MRS and MSE. The MSE chairmen, Praveen Chaudhari and Merton Flemmings, who both attended the forum, felt that the information transfer and new insights to the study provided by MRS members were extremely valuable. This feeling was also expressed by all the MSE chairmen and vice chairmen who participated. Specific mechanisms were provided for input to the study by MRS members who wished to participate. The forum provided an up-to-date overview of the progress and directions of the MSE Study to our members and to some very influential visitors who attended.

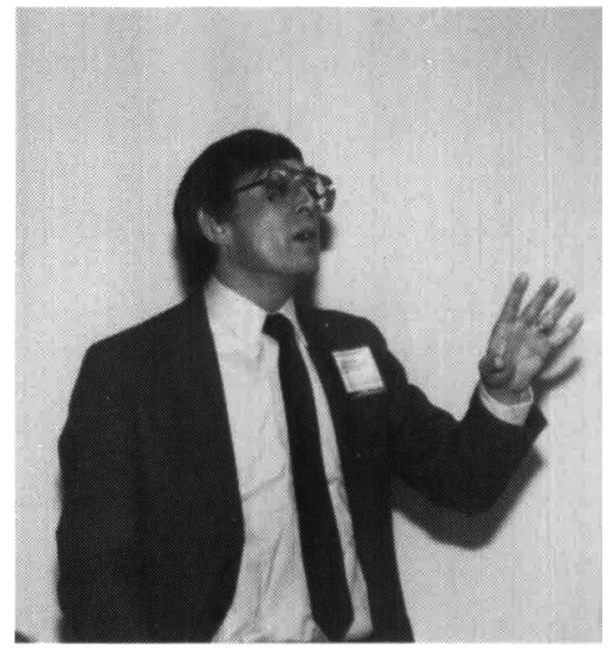

I.M. Bernstein (Carnegie Mellon Univer-) sity), chairman of MSE Study Panel 5.

This MSE Study is sure to have a significant long-term effect on materials research. Studies of this magnitude are only attempted every decade; the last such study was the COSMAT Study in 1974. The Congress and government-funding agencies will undoubtedly look to the conclusions for guidance for future policy and funding decisions. Given this it seems that all MRS members should have a vested interest in the final product. The message that ended the forum was that the study is still evolving, so MRS members, armed with the list of MSE Study panel members, can still have their opinions recorded. (See the MRS BULLETIN, Vol. XI No. 6 [1986] p. 41, for a complete list of MSE Study members.)

For those who missed the forum, similar symposia are being organized by other societies. The American Physical Society, for example, is holding one at its March Meeting in New York City, March 16-20, 1987. Also, the MSE Study is the topic of the SSSC/NMAB Joint Spring Forum to be held March 12-13, 1987, at the NAS/NAE building in Washington, DC.

B.R. APPLETON

\section{Communications on the Materials Science and Engineering Study}

A compilation of all papers contributed to the Materials Research Society which
pertain to the Materials Science and Engineering Study.
$\begin{array}{lll}\text { MRS Members: \$10 } & \text { List: } \mathbf{1 2} & \text { Foreign: } \mathbf{1 2}\end{array}$

Order from:

Publications Department

Materials Research Society

9800 McKnight Road, Suite 327

Pittsburgh, PA 15237

Telephone (412) 367-3012 